
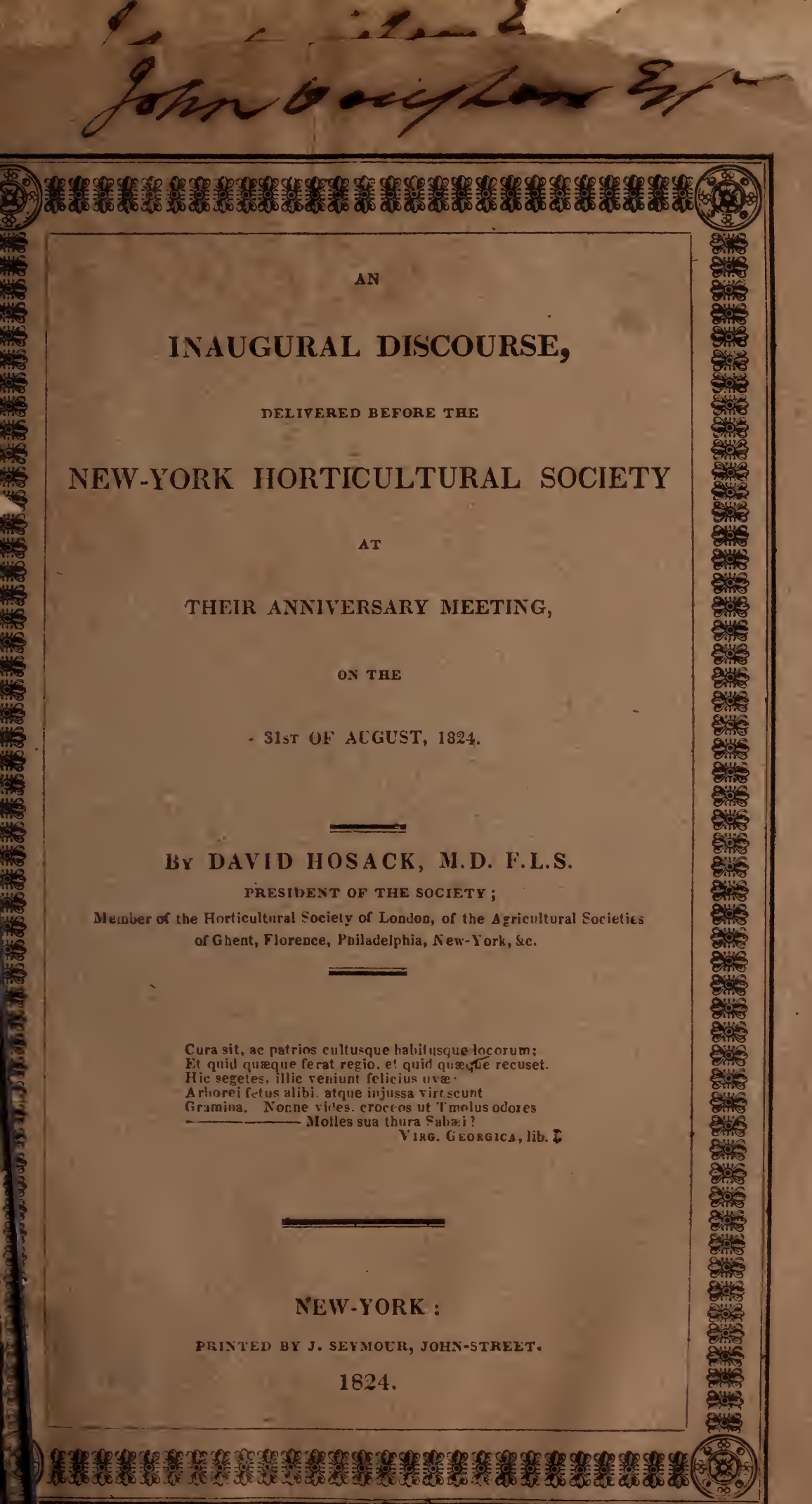


\section{Ex filluris}

SEYMOUR DURST

t' Fort nieim Amfterdam op de Manhatans

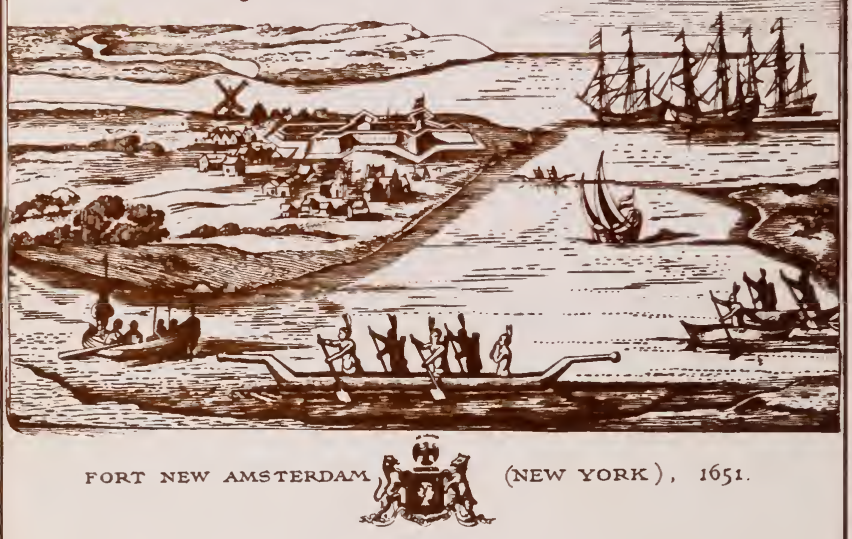

When you leave, please leave this book Because it has been said

"Ever'thing comes t' bim who waits Except a loaned book."

AVERY ARCHITECTURAL AND FINE ARTS LIBRARY Gift OF Seymour B. DURST OLd YORK LibrARy 


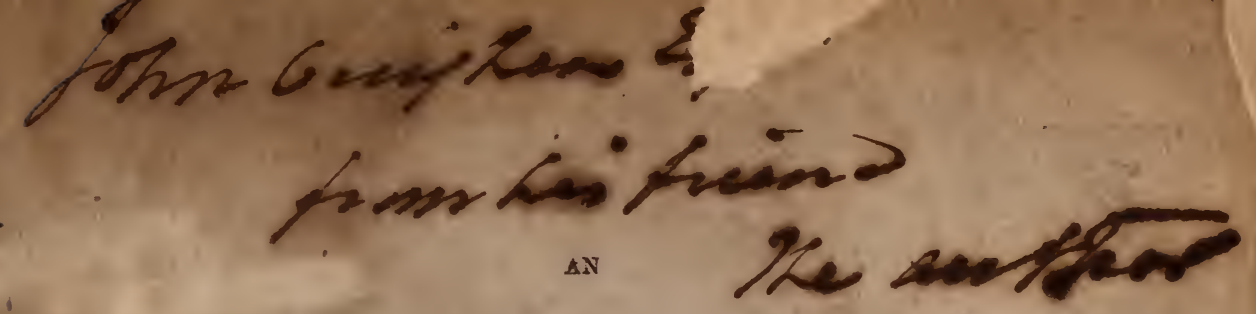

INAUGURAL DISCOURSE,

DELIVERED BEFORE THE

\section{NEW-YORK HORTICULTURAL SOCIETY}

AT

$-$

THEIR ANNIVERSARY MEETING,

OY THE

31st OF AUGUST, 1824.

BY DAVID HOSACK, M.D. F.L.S.

PRESIDENT OF THE SOCIETX;

Member of the Horticultural Society of London, of the Agricultural Societies of Ghent, Florence, Philadelphia, New-York, \&c.

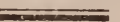

Cura sit, ac patrios cultusque habitusque locorum;

Et quid quæque ferat regio, et quid quæque recuset.

Hic segetes, illic veniunt felicius uvæ:

Arborei fetus alibi, atque injussa virescunt

Gramina. Nonne vides, croceos ut 'Tmolus odores

Molles sua thura Sabæi?

VIRG. GEORGICA, lib. i.

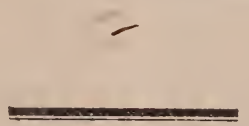

NEW-YORK :

PRINTED BY J. SEYMOUR, JOHY-STREET.

1824. 


\title{
OFFICERS
}

oF

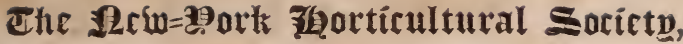

Elected on the 31st August, 1824.

\author{
David Hosack, LL. D. President. \\ The Hon. W. P. Van Ness, ? \\ Johi R. Murray, \\ J ACOB LORILLARD, \\ \}Vice Presidents. \\ Samuel L. Mitchil , LL. D. $\left\{\begin{array}{l}\text { Lecturer on Botany and } \\ \text { Vegetable Physiology. }\end{array}\right.$ \\ Peter Hattrick, Treasurer. \\ N. H. Carter, Corresponding Secretary. \\ Levi H. Clark, Recording Secretary.
}

\section{COUIVCII.}

Martiv Hoffuan, Michael Flov, Willia Phexas, Wrlliam Curr, JaMes Dick, Israel Deax, Col. George Gibis, Janes Minal, S. J. Tobras, Edward Probys, Robert Gracie, J. W. Fraxcis, M. D. Wileitim Near, Thomas Prixgle, Williat Fairbairs, Gen. Morton,
WILliam Wirgor, Thomas Hogg, JAMES M'BrAIR, JOHY M'INTYRE, Charles Oakley, Andrew Clark, Datid S. Lyox, Philip Rhivelavder, Clement C. Moore, - William Neilson, Francis Baretto, J. W. Sснитот, Jonx. Groshov, Johx Mi $\mathrm{N}_{\text {A }}$, WiLliair WILSON, Whight Post, M. D. 

At the anniversary meeting of the $\mathcal{N} e w$-York Horticultural Society, held on the 31st day of August, it was

\section{UN:ANINOUSLY RESOLVED,}

Тнат a Committee be appointed to wait on the President, and solicit a copy of the learned and eloquent Discourse this day delivered before the NewYork Horticultural Society: whereupon the following gentlemen were appointed:

The Hon. William P. Van Ness,

Martin Huffuan, Esq.

- James Buchanan, British Consul,

John R. Murray, Esq.

Professor Wright Post, M. D.

David S. Lyon, Esq.

\section{LEVI H. CLARKE,}

- Recording Secretary. 


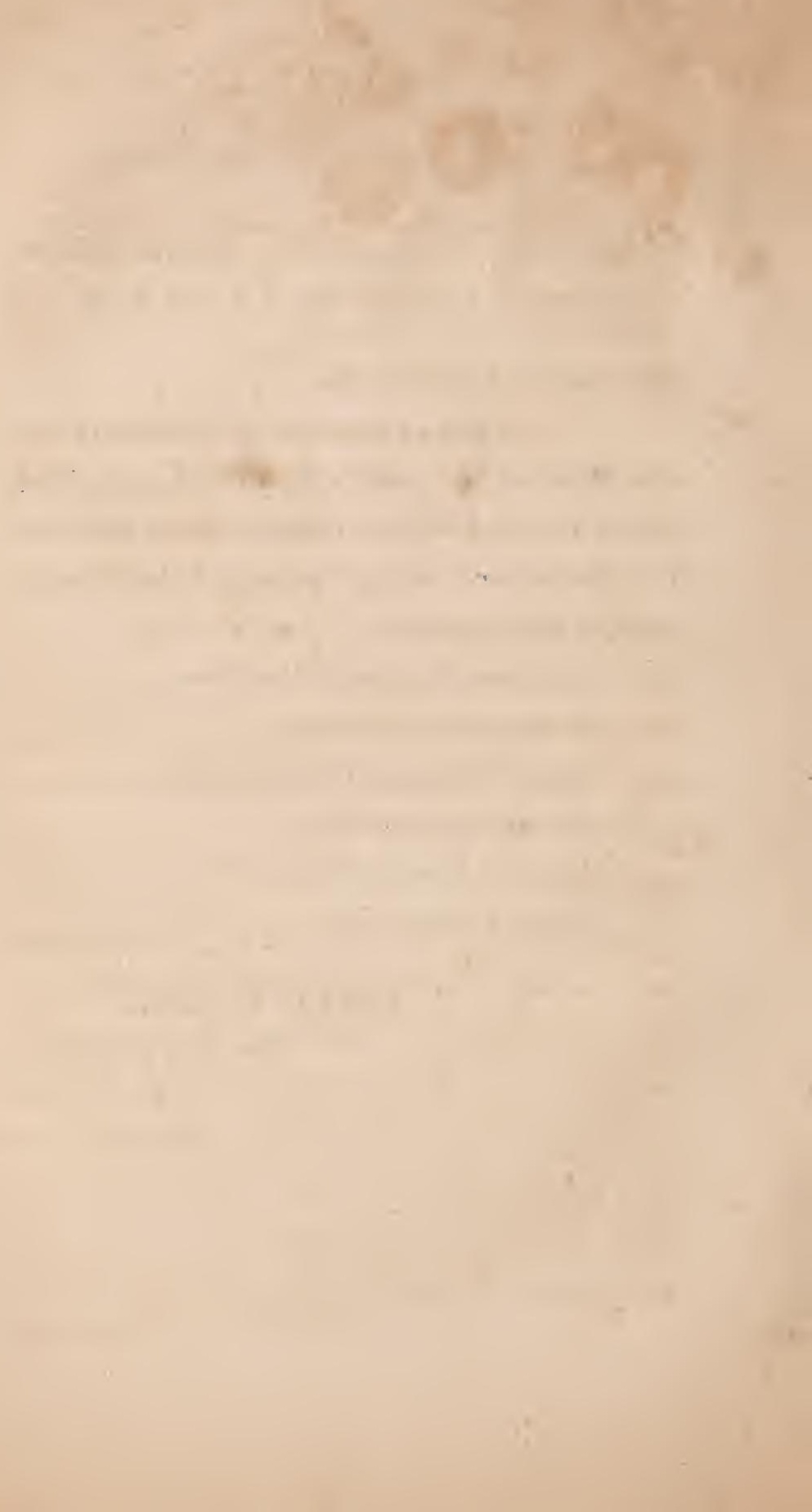


To David Hosack, M. D. President of the New-York Horticulturat Society.

NEW-YoRk, September 7, 1324.

Dear Sir,

WITI great pleasure we comply with the unanimous wishes of the New-York Horticultural Society, in presenting to you the enclosed resolution, requesting a copy of your Discourse, delivered before them on the 31st ult. We cordially concur with them in the desire expressed for its publication, as well on account of its interest and elegance as a composition, as from a wish to have more convenient access to the judicious propositions and valuable advice it submits to their consideration.

With sentiments of the highest esteem and respect,

WILLIAM P. VAN NESS,
MARTIN HOFFMAN,
JAMES BUCHANAN,
JOHN R. MURRAY,
WRIGHT POST,
DAVID S. LYON.

To the Hon. William P. Van Ness, Martin Hoffman, Esq. James Buchanan, British Consul, John R. Murray, Esq. Professor W'Right Post, M. D. and David S. Lyon, Esq. Committee of the New-York Horticultural Society.

\section{Gentlemen,}

New-York, September 8, 1824.

The Resolution of the New-York Horticultural Society affords a high gratification to my feelings; but the very flattering manner in which you have communicated it, and the character you have attached to the Discourse itself, I confess create in my mind the apprehension that you have excited expectations that cannot fail to be disappointed. I nevertheless commit it to your care, with the hope that the reader will recollect, that the laborious duties of the medical profession are to a certain extent incompatible with that attention to style and composition that are usually looked for in exercises of this nature.

I am, Gentlemen,

With sentiments of great regard and respect,

Your humble servant,

DAVID HOSACK. 
Digitized by the Internet Archive in 2014 


\section{INAUGURAL DISCOURSE.}

\section{GentLemen,}

Members of the New-York Horticultural Society,

When I lately withdrew from the situations I held in some of the literary and benevolent institutions of this city, it was my intention to have retained none, nor to have accepted of any other, saving those immediately connected with my profession. But the strong attachment, which from my youth I have cherished for botanical and horticultural pursuits, in connexion with an ardent desire to advance the interests of this excellent institution, will not permit me to decline the honour you have this day conferred upon me. Indeed, Gentlemen, I should do injustice to my own feelings, and be wanting in respect for the active exertions and abilities that already have signalized the members and officers of this Society, not to express the high gratif- 
cation $I$ leel in being selected to the station that has hitherto been so honourably and usefully occupied.

Horticulture embraces three objects. 1st. The cultivation of the plants of the table, including culinary vegetables and fruits. $2 d$. Those plants which are considered as ornamental. And 3d. Landscape gardening; or, the art of laying out grounds in such manner as may render them most conducive to utility and beauty.

In as far therefore as horticulture is not only subservient to utility, but, like the art of painting, addresses itself to the taste and to the imagination, it has very properly been enumerated among the liberal or the fine arts; and accordingly ranks among the most delightful and important of human pursuits. By Cicero it is with great propriety enumerated among the most pleasing occupations of the mind, peculiarly so in advanced life; at the same time that it is beneficial to health, by the agreeable exercise it affords to the body and the mental faculties.

In the observations I propose to make upon this occasion, I will not intrude, Gentlemen, by any detailed allusions to the history of this art. 
I might otherwise, perhaps, amuse you with the interesting accounts given of the gardens of antiquity, as well as of those of modern times; for poets have ever derived their greatest beauties, and philosophers some of their most interesting disquisitions, from this exhaustless store of human happiness. The works of Homer, Juvenal, Virgil, Milton, Shenstone, Thomson, Cowper. Mason, and the Abbé Delile, owe much of their interest to this delightful theme.

But even the charms that Milton has attached to the blissful abode of the first happy pair, or with which Homer, in his Odyssey, has embellished the gardens of Alcinous, or of Laertes, shall not divert me from my present purpose. Nor shall I attempt to ascertain the horticultural skill that was bestowed upon the garden of Cyrus, that of Attalus, the celebrated groves of the Hesperides, or the Hanging Terraces of Babylon. Nor shall I descant upon the beauties of the Academus; of the retirement in which Epicurus taught his philosophy; or that selected by Plato on the banks of the Ilyssus, celebrated as the scene of his Dialogue on Beauty. Nor shall the magnificence of the gardens of Lucullus, the 
Tusculan villa of the Roman orator, or Pliny's celebrated retreat in the Appennines, when Rome was at the summit of her glory, and the mistress of the world in arts and arms, detain me.

But referring to Xenophon, to Justin, to Virgil, to Pausanias, to Pliny, and to the writers of later days, Walpole,* Sir William Temple, Wheatly,t and to Dr. Falconer's Historical View of the Gardens of Antiquity, I pass on to remark, that very little has been effected in the science of gardening, until the last fifty years. Within that period, a number of individuals, distinguished for their taste and education, have given their attention to the study of this interesting subject, and especially in France and in Great Britain, have produced important changes in every department of horticulture, including that branch of it more especially, denominated landscape gardening. In this list, the names of Miller, Marshall, Abercrombie, Brown, Nicol, Repton, Knight, and Loudon, $\ddagger$ as well as others, whose taste and opportunities led them

* History of Modern Gardening, subjoined to his fourth volume of the Art of Painting.

f Observations on Modern Gardening.

$\ddagger$ Encyclopædia of Gardening. 
to the cultivation of this art, hold a distinguished place.

But passing over the long and justly celebrated national establishment of France, which, under the auspices of Desfontaines, J ussieu, and Thouin, embraces every thing directly and remotely connected with this department of knowledge, ${ }^{*}$ it is to be observed that it was not until 1804 that the first association of this nature was formed in Great Britain. In that year, under the patronage of the late Sir Joseph Banks, the Mecænas of his age, the Earls Dartmouth and Powis, Sir James Edward Smith, Mr. Thomas Andrew Knight, Mr. R. A. Salisbury, and Mr. Joseph Sabine, the Horticultural Society of London was instituted; and in 1809, by the exertions of Dr. Andrew Duncan, the able and learned professor of the institutes of Medicine in the University of Edinburgh, the Caledonian Horticultural Society was formed in that city. The enterprise and abilities of that venerable character, who, like Celsus of old, united great horticultural knowledge with his profession-

* Histoire et Description du Muséum Roval d'Histoire Naturelle, par M. Deleuze. 
al attainments, aided by the Duke of Buccleuch. the Earl of Wemyss and March, the Honourable Sir John Sinclair, Sir James Hall, Sir George Stewart Mackenzie, and others of the Scottish nobility and gentry, have done much in directing their countrymen to the cultivation of this art.

By the friendly intercourse of the members of those institutions, and the emulation that has been excited among those numerous bodies, each consisting of many hundred members, horticultural knowledge has rapidly increased, and the most beneficial results have been experienced throughout the kingdom of Great Britain.

Each of these institutions has published many volumes of communications, and much has thereby been effected by diffusing a knowledge of the principles and practice of gardening, not only inviting the attention of gentlemen of leisure to subjects so immediately conducive to the support and happiness of man, but exciting among the cultivators of the garden and the field a spirit of emulation that has been immediately profitable by the addition it has made 
in the quantity, and the improvements it has effected in the quality, of the products of the soil.

The London Horticultural Society has already published several quarto volumes, embracing many important subjects in all the departments of culinary, fruit, and ornamental gardening, and those too illustrated by coloured engravings, executed in a style of magnificence highly creditable to the skill of the artists, and alike honourable to the institution and the nation.

The Scottish Society has also published some volumes of great merit, and although executed with less attention to the type and elegance of manner, have been the means of spreading very exterisively the knowledge both of the principles and the practice of horticulture.

But a very few years have elapsed since the Society now assembled, was first instituted. In September 1818, a small number of the more enterprising and intelligent of the practical gardeners and nurserymen in the vicinity of this city, convened for the purpose of introducing such improvements in the cultivation of our vegetable productions, as they conceived were called for, and which, by their education and 
abilities, they felt themselves competent to effect. This association was in the first instance entered into without the most distant view of attracting public notice. But as these improvements proceeded, they acquired notoriety, and the views of their authors expanded with their success. They consequently became desirous that the knowledge of the improvements they had effected might be preserved and extended for the good of the community. Many of the most respectable gentlemen of our city, who are in the habit of passing a portion of their time, during the warm season of the year, at their villas in the neighbouring country, and who are attached to horticulture, also joined in this association; and, that their labours might become still more extensively useful, as well as for the purpose of securing to every individual the reward due to him for his active and successful exertions, it was now proposed, that they should form themselves into a regularly organized institution. This was accordingly effected.

Such, gentlemen, were the humble and unostentatious beginnings of the New-York Horticultural Society, which, within a very short space. 
of time, has been the means of increasing the variety, and of improving the quality of the vegetables of our table; of totally changing the face of our markets; of introducing a great number of valuable fruits; of augmenting the number and variety of ornamental plants, both indigenous and exotic, and thereby of spreading a taste for this innocent, yet instructive and delightful source of enjoyment.

In the year 1822 this Society made an application to the state legislature for an act of incorporation.

The legislature, perceiving the beneficial results that had been produced, and were to be expected to thie community, from an institution of this nature, and as it was the first that had been established in the United States, they with great unanimity granted an act of incorporation, embracing all the provisions that had been solicited, and were deemed necessary to carry such institution into successful operation.

In conformity with this instrument, the gentlemen composing the association immediately convened, and appointed a committee to prepare a constitution and code of by-laws for the govern- 
ment of the same. These have recently been completed under the direction of the Society; printed for the use of the members; and are now ready for distribution.

While these measures were in progress, owing to a train of unpleasant circumstances, the recollection of which we hope may never be revived, a few gentlemen thought it expedient to form a new establishment, under the title of the New-York State Horticultural Society, and precisely, as they themselves set forth, for similar purposes in all respects with those of the original institution now in successful operation, and under which we are happily assembled. I well know that the greater number of those who entered into the new association were, at the time they expressed their willingness to concur in its establishment, altogether uninformed of the ulterior views and proceedings of the already existing society, and have since expressed their desire that the two associations may be consolidated, and their entire willingness to lend their aid in effecting such union. This event is still to be desired; and on our part I feel authorized to say, as expressed in our proccedings, will be cheerfully 
acceded to upon terms of reciprocity. The views and objects of the two institutions being, in all respects, similar, one is certainly superfluous, and creates a very unnecessary call upon the contributions of a generous public. I cannot therefore but indulge the belief, that the members of both institutions will make the sacrifice of any personal or interested considerations, and combine their efforts for the purpose of effecting an union so desirable, which promises to be productive of great good to the community, and an honour to our city and state. After these preliminary remarks, I solicit your attention to the consideration of a few of the most prominent subjects which appear to me to claim the notice of this Society.

In the first place, as this Institution is altogether of a practical nature, and has for its objects practical improvements in the culture of plants, it is obvious that a garden should be established in the vicinity of this city, as a repository for the vegetable productions that may be received by the Society, whether derived from foreign countries, or the growth of our own soil. As subservient to the great purposes for which this Society has been 
instituted, and as already stated, these objects are numerous, a piece of ground should be selected, which, from its extent, varicty, and situation, would be capable of affording all the advantages that can be contemplated in an establishment of this nature.

1st. It should be sufficiently extensive to contain all the variety of fruit-trees and shrubs, not only that they may have all the advantages of space nccessary to their growth, but that they may be exhibited to the visitor or cultivator under the most advantageous circumstances. And upon this subject let me remark, that it becomes highly important, in an institution of this nature, to ascertain by a regular series of observations the characters of the different fruits that are cultivated, and to determine what are the different species and varieties well established as such: for in horticulture, as in medicine, empiricism exists, which can only be controlled by an association of men, well instructed in their profession, and who by long observation and experience have become familiarly conversant with the subject. It is owing to the want of a proper examination of fruits by competent men, that we find, 
instead of a standard nomenclature, our cata* logues of fruits filled with an almost infinite number of supposed varieties, that have no existence but in the whim of the cultivator, or which has originated in sinister or sordid designs.

2d. Compartments should be provided for all the esculent vegetables of the table, in whatever form they may exist, whether gramineous or herbaceous.

3d. Provision should be made for the culture of those plants that are most useful in medicine, or are subservient to the arts, or are employed in manufactures.

4th. To these should be added, for the purpose of diffusing a taste for the productions of nature, and of exciting the attention of our youth of both sexes to botanical inquiries, and of contributing to the beauty and elegance of the establishment, a collection of the most rare and ornamental plants that can be procured, both indigenous and exotic. While therefore we shall thus have it in our power to bring into one view, for the information of the stranger or for the purposes of exchange with foreign correspondents of the Institulion, the native productions of our 
varied climate and country, we should also be provided with suitable conservatories for those plants which may be introduced from abroad. And I may add, that the buildings thus erected should be constructed agreeably to the most correct principles of architecture; for every such edifice, in a place of great public resort, will necessarily have its influence in forming and directing the general taste of the country.

5th. The whole of this Institution should be surrounded with a belt of forest trees and shrubs, foreign and domestic.

6th. Connected also with these means of instruction, a building should be set apart, appropriated as a Lecturing Room, and supplied with a Library, where access may be had to every work of importance, in any of the branches appertaining to the subjects of botany, horticulture, vegetable physiology, the philosophy of vegetation, or the principles of agriculture; and in forming such library, you will not omit to place upon its shelves the Memoirs and Transactions of the London and Edinburgh Horticultural Societies, as well as those of France and other establishments of the like nature on the continent of Europe; the 
transactions of the agricultural institutions of this country-of the states of Pennsylvania, NewYork, Massachusetts; and the writings of Skinner, Southwick, Thacher, Coxe, Dean, Taylor, Elliott, Nicholson, and others, should be included in such collection.

7th. Attached to this library, should be a cabinet set apart for an Hortus Siccus, or Herbarium, and containing our most valuable plants, preserved, arranged, and designated, in the manner that has been adopted by professor Desfontaines, at the Jardin des Plantes at Paris.* The remark I have heard made by that distinguished practical botanist, the late Sir Joseph Banks, that even an imperrfect dried specimen is preferable to the best painting, is a striking evidence of the importance of such collection. Nevertheless, the productions of the pencil, in delineating the most rare and valuable plants of the garden, should be also carefully collected, as preparatory to the publications which may hereafter issue from this establishment.

* See Journal of the Horticultural Tour in Flanders, Holland, and the North of France, by a deputation of the Caledonian Horticultural Socicty. 1823. 
You have wisely provided a lectureship on botany and vegetable physiology. A new subject of inquiry here opens to our view, and merits the particular notice of this Society. I refer to the philosophy of vegetation, the doctrines and principles of agricultural chemistry, the composition of soils, and the operation of manures, all which have recently engaged the powerful mind of Sir Humphrey Davy and other distinguished men. These are subjects, which, in addition to the technical arrangements entered into by the Lecturer, will also be embraced in his course of instruction, and cannot fail to be productive of important results.

8th. Another advantage which such an establishment should possess, is that of exemplifying the principles of Ornamental Planting, or Landscape Gardening. The ground should be selected of such form and variety as will admit of such decoration. And in the cultivation of the various plants of the collection, their distribution may ever be rendered subservient to this great object, and thereby become the means of spreading extensively among our citizens a taste for one of the highest recreations that the human heart can 
receive, and one which will go far in the improvement of the moral principle, and in diverting the mind from pursuits of a less worthy nature; for the mind that is not actively engaged in virtuous pursuits will most probably be occupied with those of a contrary character.

9th. In this Institution, doubtless, attention will be given in forming a system of instruction necessary in the education of the complete gardener, in the manner that has been constantly practised in some of the institutions of Europe. For this purpose, apprentices should be received for a certain period of time, affording them the advantages not only of being instructed in the cultivation of all sorts of culinary and ornamental plants, but of being made practically acquainted with the different operations of pruning, training, budding, grafting, layering, and transplanting, as well as the general principles of ornamental gardening.

A professor of drawing should be attached to the establishment, whose duties should be, not only to make delineations of any plants of great value or beauty that may be introduced into the collection, but who would also deliver a course 
of lectures upon his art, to the pupils who might resort to this establishment for instruction.

Instead then of looking to Europe for gardeners, which has hitherto been the custom of our country, we should at such school educate a sufficient number of our own citizens to supply all the wants that may be created. Another advantage that must obviously flow from such an organization, is, that the natives of our soil, being necessarily better acquainted with the climate and the vicissitudes of our seasons, are consequently, with the same opportunities of education, better qualified for the duties of their occupation than the foreign gardener, who requires the residence of years to instruct him in this important part of his profession.

II. Another, among the most important subjects which will invite our attention, is the cultivation of our native fruits.

When we recollect, to use the languadge of Mr. Knight, that the golden pippin was derived from the austere crab of the woods, and that the numeruus varieties of the plum are the produce of the native sloe, we are taught the importance of giving our attention to the numerous and hitherto 
unexplored productions of our native wilds, and are encouraged to believe that many important additions may be made to the table by the enterprise of our members in changing, by culture, the character of our domestic fruits. When, too, we see that many trees have been rendered capable of ripening their fruits in climates colder than their native country, and that many have been assimilated in their habits to their newly adopted climate, and as the horticulture of one country must essentially differ from that of another, and must vary in its nature and objects, depending upon climate, soil, and other local circumstances, it is important for us to institute a series of observations and experiments, with the view to ascertain how far many plants, which are now the staple productions of the south, may be acclimated to higher degrees of latitude. The successful experiments of $\mathrm{Du} \mathrm{Hamel}$, in France, are very instructive upon this subject, and will admit of extensive application in the United States.

The cultivation of the vine, in a peculiar manner, merits the notice of this Society. 


\section{8}

This subject has been frequently recommended by many eminent horticulturists, and in several instances attempted, but in some without the success which had been anticipated, and this probably owing to the measures not being adopted or understood that are necessary to its accomplishment. Great praise is due to $\mathrm{Mr}$. Adlum, a distinguished cultivator of the vine at Georgetown, District of Columbia, to Mr. Eichelberger, of Pennsylvania, * to Mr. Divers, of Charlottesville, Virginia, to Dr. Wilson of Clermont, and to Colonel Gibbes, an agriculturist in the vicinity of this city, as well as some other of the members of this Society, for the attention they have given to the cultivation of the grape.

Among the wants in our domestic economy, none are more conspicuous or lamentable than that of some agreeable beverage which may supersede the use of ardent spirits, the inordinate and extensive use of which has long been among the opprobria of our countrymen. It is a. common remark, and is fully justified by the experience of European nations, and the high

* American Farmer, vol. V. p. 251. 
authority of that illustrious writer upon political economy, Dr. Adam Smith, * that the inhabitants of countries where the vine is cultivated and the juice of the grape the common beverage of the people, are free from the vice of intemperance. It is remarked by that acute observer, "that the inhabitants of wine countries are, in general, the soberest people in Europe. Witness the Spaniards, the Italians, and the inhabitants of the southern provinces of France." "On the contrary," he observes, "that in the countries which, either from excessive heat or cold, produce no grapes, and where wine consequently is dear and a rarity, drunkenness is a common vice; as among the northern nations, and all those who live between the tropics, the negroes, for example, on the coast of Guinea." The cheapness of wine, he adds, seems, therefore, to be a cause, not of drunkenness, but of sobriety. I was told by the late Dr. Hugh Williamson, that Mr. Jeflerson assured him that, during his residence, as American minister, in France, he never met with but one instance of intoxication.

* Wealth of Nations, vol. II. p. 296. 
An English geritleman* of great intelligence, who has recently travelled through Spain, within a few days informed me, that, with the exception of those who held intercourse with British or American seamen, who are in the constant use of spirituous liquors, he never met with a drunken Spaniard.

It seems, therefore, to be equally the dictate of patriotism and humanity, to eradicate from our country so grievous a reproach. This Society, gentlemen, by their attention to this subject, may be the means by which thousands of our fellow-men may be reclaimed from a most pernicious and disgraceful vice, alike ruinous to domestic happiness, and destructive of the moral character of the nation.

The question then presents itself, is our climate capable of affording the grape in sufficient quantities to furnish wine as the daily beverage of the inhabitants of the United States? or do we possess resources for this purpose in the native fruits of our country?

* Charles Waterton, Esq. of Walton Hall. 
From the experiments already made in different parts of this country, this question may, I believe, be answered in the affirmative.

The experiments made in the southern and western states, as we are informed by $\mathrm{Mr}$. James G. Hicks, a writer in the American Farmer, show that wines of most excellent quality, both Claret and Madeira have been produced. "I am well convinced," says the writer, "from my experience in the business, that a vineyard, in an eligible situation, well cultivated, will yield from three to five hundred gallons to the acre; and one hand can with ease cultivate five acres, except gathering; and I have no doubt but the wine would be equally as good as that which is imported at the same age. I have sold my wine, when only two years old, for two and a half, and three dollars per galion."

"Should the people of Kentucky and Tennessee turn their attention to this business, they will not only be enabled to stop the importation of wines, but will be enabled to furnish the eastern and northern states with this article 
cheaper than they can import it." Further and more recent observations made by Mr. Adlum, already referred to, by the late Mr. Thomas Roach of Hartford, by the sect of Harmonists from Suabia, now cultivating the vine to a great extent in Indiana, and the extensive establishment at Cacahokia, now Illinois, also abundantly evince the capacity of our soil and climate in the production of wines of the best quality from various grapes, both foreign and domestic.

It is remarked by Mr. Madison, * whose observations on the subject of agriculture, to which he now devotes his retirement, are no less profound and deserving public attention than were those which occupied his mind during his public life, when cngaged in the weightier concerns of the nation, "That the practicability and national economy of substituting, to a great extent at least, for the foreign wines, on which so large a sum is expended, those which can be produced at home, without withdrawing labour from objects better rewarding it, is strongly illustrated by the experiments and statements made upon this subject. 
The introduction of a native wine is not a little recommended, moreover, by its tendency to substitute a beverage favourable to temperate habits, for the ardent liquors so destructive to the morals, the health, and the social happiness of the American people; and it may be added, which is so expensive to them also: for, besides the actual cost of the intoxicating draughts, the value of the time and strength consumed by them is of not less amount."

It has also been proposed by many of our farmers, and numerous experiments in various parts of the United States show the propriety of the suggestion, to furnish a substitute for spirituous liquors by obtaining, from the fermentation of some of the native fruits of our soil, as from those which are now extensively cultivated in our fields and our gardens, wines which might take the place of the more expensive produce of the grape.

The apple,* the pear, the blackberry, the currant, the raspberry, the gooseberry, and the elderberry

* See an important communication on the subject of domestic wines, by Dr. Samuel L. Mitchill; and observations on the same subject. by Dr. Rush, in the appendix to this discorarse. 
liave all been successfully made use of for this purpose in various parts of this country, and wines highly agreeable, obtained from these fruits, are now prepared in considerable quantities, offered for sale in our cities, and when fashion, and the patronage of influential individuals, and of public institutions shall recommend them to our citizens, 1 have no doubt that, with the improvements they will receive in their preparation, and which will be proportioned to the demand, our country will be abundantly supplied with domestic wines calculated to produce all the cordial and salutary effects of, without the evils arising from, the stronger wines of Madeira or France, or the use of ardent spirits.

My time will not permit me to enlarge upon this interesting topic.

In conclusion, Gentlemen, allow me here to remark, that the city of New-York possesses advantages and facilities for the various objects of our Institution, greater than can be obtained in any other part of the union. By our commerce and our navy, we have continued intercourse with every part of the globe. The gentlemen employed in the public service of 
their country, and in the recently established communications with the different parts of the world, are, for the most part too, men of excellent education and inquiring minds, and not wanting in patriotism, whether employed in the battles of their country, or in cultivating the arts of peace.

Circulars prepared under the direction of this institution, and placed in their hands when they depart from our shores, would secure to us, in a very few years, the vegetable productions of every part of the habitable globe, and in the intercourse between this city and the other parts of the union, so unceasing is the communication; and at all seasons of the year, that the benefits we may through these channels receive in this city and state will immediately be diffused through our common country.

But this is not all. Science, which in one shape or another, grasps all human improvements, and presses them into the service of a common cause, will in return receive direct aid from the stupendous artificial works now nearly completed in this state for the promotion of trade and intercourse. I cannot be mistaken 
in my allusion. I speak, Gentlemen, of the great Western Canal, and the minor communications which are connected with it. The vast and fertile regions of the west are yet to be explored by the sons of genius and research. The secrets of nature are yet to be unfolded. Her hidden treasures, her countless varieties, and her unnumbered beauties are yet to be presented.

The territory of the great lakes and of the western rivers is a world of itself. How important, then, that we are thus approximated by the gigantic work which I have mentioned. Our course is now open to the depths of the wilderness. In peace and in comfort we can not only visit the walks of civilization and refinement, the towns, the villages, and the cities which have recently appeared in the west as if they were called forth by the potent hand of enchantment; but we can also gratify our curiosity and our love of science, by examining regions where the footstep of the naturalist has never left an impression, or science gleaned a treasure. I say then that the magnificent internal improvements of the state of New-York are tributary to our 
objects. They facilitate the execution of our laudable designs. They multiply, on a stupendous scale, the means of intercourse, and literally annihilate distance and expansion of territory.

And while on this subject, and removed, as I am, by my professional pursuits, from the sphere of politics and the vortex of party collision, can I justly refrain from indulging in a passing expression of my respect for the statesman whose profound reflections, deep penetration, and energy of character have been subservient to the commencement, the prosecution, and the near completion of these unparalelled projects?

The name of Cunton is not only endeared to the votaries of science by his devotions at her shrine, but rendered doubly so by the indirect aid which he affords to her interests by his splendid plans of public policy; plans at once great, practicable, and unrivalled in the age which has produced them. 



\section{A P P E N D I X.}

Letter from Samuel L. Mitchile, M. D. to David Hosack, M. D. on the improvement of Orchards, Apples, and Cider.

New-YoRK, September 3d, 1324.

MY Dear Sir,

Since the apple, as an article for furnishing a vinous liquor, has been referred to me for consideration, I give you with pleasure my opinion, as lecturer on botany and vegetable physiology to the Horticultural Society. The tree affording this fruit, and the agreeable drink the latter yields by fermentation, have long exercised the industry and skill of man. And in the convenient soils of the middle latitudes, many proprietors have considered their culture as matters of high moment.

Nor is this an object of surprise. The apple-tree, in my judgment, produces some of the best fruit in the world. Many varieties gratify the sight by their diversity of figure, size, and colour; others satisfy the smell, by their fragrance, of a delicious quality; while yet others again recreate the palate with their exquisite flavour. 
The expressed juice is well known in one of its fermenting stages as cider, and in another as vinegar.

If there is any room for wonder in the case, it is that more stress has not been laid upon the cultivation of the apple, especially in our parts of North America. It seems to me that the region between James River and the Kaatskill Mountains, including New-Jersey and all the southern district of New-York, is peculiarly favourable to orchards of this kind. The trees thrive well; are long-lived; bear the heat, cold, and vicissitudes of the weather; run into endless varieties, which varieties are perpetually on the increase; and they bear grafting and inoculation to admiration.

And still, with so many good qualities, the apple has not risen so high in public estimation as it deserves. There are two obvious reasons for the neglect it has experienced.

One cause, at least among those who speak the English language, is connected with the name it bears. The word cider does not convey to the mind the idea of a wine, or vinous liquor. However excellent it may be, it is consumed simply as cider; and is not exalted to the rank and dignity of wine. The German tongue is more happy in this respect; for it denominates cider by the name of Apfel wein, or apple wine. And if we could establish, from "malus," the Latin name for the appletree, or "malum," an apple, such a title as malic wine, instead of cider, I am confident its character and credit would be increased. 
The other cause is the preference given to the grape, and its produce. The vine, which produces this fruit, has, like the apple, branched into numberless varieties, and proved itself capable of cultivation over most countries of Southern, and some of middle Europe. The vine has steadily there kept pace with improvement and civilization. The more common forms of the fermented drink procured from its fruit have been deemed necessary to life; while the more exquisite modifications are classed among the most precious luxuries. It has also gained, and deservedly, the consideration due to a valuable and important medicine. In addition to the intrinsic worth of this product, which may be called "grape wine," or "wine of the grape," our manners, habits, and customs, so much resemble those of the people from whom we have descended, that we can hardly be friendly or sociable without it.

Attempts were, soon after the settlement of certain colonies, made to render this country independent of all others, by rearing and dressing the vine. Yet the project, though urged by its advocates early in the seventeenth century, at least two hundred years ago, has hitherto been carried but partially into execution. This has probably arisen from the great ease with which wine has been imported from foreign ports and places; and from the readiness with which our bread-stufis, fish, and other kinds of food, are exchanged for this sort of drink.

I am satisfied, from long and extensive observation, that our country, south of the latitude of about forty-one, 
degrees, or perhaps a little more, will sustain the grapevine. The fruit produced in the county of New-York and its vicinity, is abundant and delicious. The liquor prepared by Mr. Legaux, from his vineyard near Philadelphia, proves the vine to afford good fruit. The like favourable report has been made of the Swiss settlement at Vevay, under John James Dufour and his associates. And more recently, Thomas Worthington, Esq. has produced for our tasting an elegant wine, partaking of the qualities uniting claret to burgundy, from his own plantation in the state of Ohio. The publication promised by William Lee, Esq. a gentleman well acquainted with the cultivation of the vine, and especially in the tracts watered by the river Garonne in France, may be expected to contain the most correct and recent information on the subject.

But it is not to exotic vines only that we may look. Our indigenous spccies'and varieties promise something valuable by culture. The scuppernong of North Carolina, from the place where the river Roanoake empties into the Sound, is already known and approved. The luxuriance of the plants in Alabama, may be understood by Mr. N. Bicknell's letter, of a late date, from Clarkesville. "The grape-vines grow to an enormous size, and rise to the tops of the tallest pines. I have seen them as large as my thigh, ten feet from the ground. In an account I read a few days since of the progress of the vinecultivation in Pennsylvania, it is stated that cuttings are planted, which bear a few grapes the third year. I was conversing with a gentleman here on the subject, who 
intormed me, that learning a graft would take on the vine, he dug up some vines in the woods, set them out, and grafted them; and that one of them produced two bunches the first year, and bore abundantly the second. There is a native kind here, of delicious flavour, having tartness enough to prevent cloying the appetite. The bunches are very long, and three hundred and sixty-four grapes of a large size were counted upon one of them. I wish it could be ascertained whether grapes take the graft," \&c.

I consider it perfectly practicable for wine of the grape, both of the foreign and domestic stocks, to be produced in the proper soils and climates of the United States, whenever the agricultural citizens shall turn their attention that way. If I should hesitate or object to this mode of improving land, it would be upon other ground. I have ever considered a country abounding in grass and grain, as affording the greatest amount of enjoyment to those who do the work. The beast and his master are more plentifully fed. The abundance which passes from the field into the barn and the granary, shows itself in the number and fatness of the animals, in the excellent condition of buildings and fences, in the comforts and even elegancies of the mansion, and in the income and credit of the owner. This association of a grazing and bread-stuff culture with the maximum of enjoyment for a free and republican people, is almost indelible in my mind. 'Every additional acre thus improved is an additional evidence of prosperity, in my sense of the word; and every acre taken from this culture, and turned to 
something else, even to the culture of the vine, may be considered as withdrawn from the more interesting business of yielding food and its accompaniments.

The planting of the apple-tree is not liable to this remark. It is consistent with the full exercise of the plough and the hoe, the scythe and the flail, the mill and the tannery. The manifold uses of this fruit are universally known. How, nevertheless, can I forbear to mention the Swaar-apple of Poughkeepsie, the Spitzenbergh of Kingston, and the Pippins of Newtown? New-Jersey has become famous for the cider of Newark. Virginia is proud of her Hughes's crab. New-York dwells with satisfaction upon the praises of Paine's red-streak: and our fellow-citizen, William Cumberland, has been specially occupied for a considerable time in practical trials to bring cider to that degree of purity and excellence, entitling it to the appellation of apple wine.

I really wish, that farmers would turn their thoughts more seriously to the apple, and its vinous products.

The points more immediately worthy of observation, are, among others, the following :

1. The selection of the best fruit for making the particular ciders.

2. The rearing of a sufficient number of trees, to produce a good vintage.

3. The securing thereby the ripening of the apples, at the same time, and at the proper season.

4. The separation of the select apples from all unripe ones, and from all acerb varieties.

5. The removal of all dirt and heterogenous matters. 
6. Attention to the clean and inodorous condition of the casks and vessels.

7. Proper attention to the process of fermentation, that it be checked by sulphureous fumes, or by cool vaults, before it goes too far.

8. The construction of cellars or recesses along sidehills or slopes, for keeping and ripening the liquor.

9. Due attention to fining, racking, decanting, and precaution requisite for rendering it as complete as its nature will admit.

Whenever the state of society shall arrive, and I hope it is not very remote, when the apple shall receive that culture and management of which it is susceptible, there will be produced among ourselves liquors or drinks far superior to the greater part of the imported wines, and approaching, with due care and art, the virtues of the most highly esteemed and fashionable of them all.

I avail myself of this opportunity to congratulate you on the good already done by the members, and the prospect of an enlargement as well as a continuance of their useful labours : and I conclude my communication by a renewed assurance of my good feeling and high regard.

\section{SAMUEL L. MITCHILL.}


Extract from Observations on the Domestic Wines of the United States, by the late Dr. RusH.*

"It is to be lamented that the grape is not yet sufficiently cultivated in our country, to afford wine for our citizens; but many excellent substitutes may be made for it, from the native fruits of all the states. If two barrels of cider, fresh from the press, are boiled into one, and afterwards fermented, and kept for two or three years in a dry cellar, it affords a liquor, which, according to the quality of the apple from which the cider is made, has the taste of Malaga or Rhenish wine. It affords, when mixed with water, a most agreeable drink in summer. I have taken the liberty of calling it Pomona Wine. There is another method of making a pleasant wine from the apple, by adding four and twenty gallons of new cider to three gallons of syrup made from the expressed juice of sweet apples. When thoroughly fermented, and kept for a few years, it becomes fit for use. The blackberry of our fields, and the raspberry and currant of our gardens, afford likewise an agreeable and wholesome wine, when pressed, and mixed with certain proportions of sugar and water, and a little spirit, to counteract the disposition to an excessive fermentation. It is no objection to these cheap and home-made wines, that they are unfit for use till they are two or three years old. The foreign wines in common use in our country, require not only a much longer time to bring them to perfection, but to prevent their being disagreeable even to the taste."

* See his Inquiry into the effects of ardent spirits upon the human body and mind. p. 17. 



